\title{
Polymerization of 4-Vinyl-1-Cyclohexene Diepoxide by Rhenium Carbonyls Compounds
}

\author{
Ideisan I Abu-Abdoun* \\ Department of Chemistry, University of Sharjah, Sharjah, United Arab Emirates
}

Submission: February 02, 2019; Published: March 06, 2019

*Corresponding author: Ideisan I Abu-Abdoun, Department of Chemistry, University of Sharjah, Sharjah, United Arab Emirates

Summary

The polymerization of 4-vinyl-1-cyclohexene diepoxide (4-VCHD) by rhenium carbonyl, $\operatorname{Re}(\mathrm{CO}) 5 \mathrm{X}(\mathrm{X}=\mathrm{Br}, \mathrm{Cl})$ and dirhenium decacarbonyls $\operatorname{Re}_{2}(\mathrm{CO})_{10}$ has been carried out photochemically at $25^{\circ} \mathrm{C}$, and thermally at 25 and $75^{\circ} \mathrm{C}$ witout cocatalysts. The effects of initiator structure, concentrations, and reaction temperature and time on the polymerization rate is reported here.

Keywords: 4-vinyl-1-cyclohexene diepoxide; Rhenium Carbonyl; Photoinitiated Polymeriation

\section{Introduction}

Diepoxy resins have found important commercial applications in UV radiation curing of surface coatings; a dhesives and in the plastic industry $[1,2]$. Photoinitiated cationic ring-opening polymerizations of cyclohexene oxide (CHO)1 (Figure 1) was conducted using dirhenium decacarbonyl [3] and rhenium carbonyl halides [4] without a cocatalyst. 4-vinyl-1-cyclohexene diepoxide 2 is used as a reactive diluent's for diepoxides and epoxy resins; this monomer is expected to form crosslinked polymers, if both epoxide groups are polymerized. Cationic photoolymerization of 4-VCHD by diphenyliodonium hexafluorophosphate was carried out and a mixture of crosslinked and benzene soluble polymers were obtained [5], cationic thermal polymerization by BF3. $\mathrm{O}\left(\mathrm{C}_{2} \mathrm{H}_{5}\right)_{2}$ [6], and it has been reported that two epoxy rings can be opened for polymerization selectively by radiation, but not by chemical initiators.

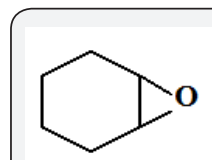

(1)

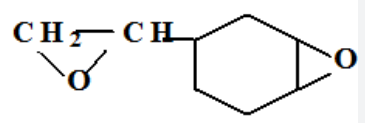

(2)
Figure 1: Structure of cyclohexene oxide (1) and 4-Viny-1cylohexne diepoxide (2).

In this paper we report on the polymerization of 4-VCHD (Table 1) by rhenium carbonyl, $\operatorname{Re}(\mathrm{CO})_{5} \mathrm{X}(\mathrm{X}=\mathrm{Br}, \mathrm{Cl})$ and dirhenium decacarbonyls $\operatorname{Re}_{2}(\mathrm{CO})_{10}$ photochemically and thermally without cocatalyst Table 2 . Insoluble polymer was obtained in photo or thermal polymerization even at low conversion of monomer.
Table 1: Photopolymerization of 4-VCHD (bulk), initiator effect on the gel time. [initiator] $=2.50 \times 10^{-3} \mathrm{M}$.

\begin{tabular}{|c|c|}
\hline Catalyst & Gel Time \\
\hline $\operatorname{Re}_{2}(\mathrm{CO})_{10}$ & 15 minutes \\
\hline $\operatorname{Re}(\mathrm{CO})_{5} \mathrm{Cl}$ & 5 minutes \\
\hline $\operatorname{Re}(\mathrm{CO})_{5} \mathrm{Br}$ & 15 minutes \\
\hline $\operatorname{Re}(\mathrm{CO})_{5} \mathrm{I}$ & 14 hours \\
\hline
\end{tabular}

Experimental

\section{Materials}

4-vinyl-1-cyclohexene diepoxide (Fluka) was distilled over calcium hydride $\left(\mathrm{CaH}_{2}\right)$, and the middle fraction was collected. Solvent dichloromethane (Fluka) were dried over calcium hydride and distilled before use. Rhenium carbonyls were obtained from Pressure Chemical Company and used as received.

\section{Instruments}

Ultraviolet spectra were obtained on a Cary 2300 spectrophotometer. Infrared spectra were recorded on a Nicolet 50xB FT-IR spectrophotometer.

\section{Polymerization}

Photoinitiated polymerization was carried out in a $15 \mathrm{~mm}$ diameter Pyrex tube using a tight syringe for monomer addition; a homogeneous solution was formed, the reaction tube was then closed with rubber septum, and irradiation was carried out using a merry-go-round photoreactor, Model RPR 100, which rotates 
continuously by a motor and is surrounded by 16 Hanovia 450 Watt, medium pressure mercury. The light source was equipped with $350 \mathrm{~nm}$ wavelength tubes. The samples were placed in the holder and irradiated for the required period.Thermal polymerization was conducted by placing the reaction tube in a water bath at the required temperature for the time indicated in dark. Isolated polymer was washed with dichloroethane, filtered, dried and weighed. The rate of polymerization was calculated gravimetrically as a function of reaction time [7].

\section{Results and Discussion}

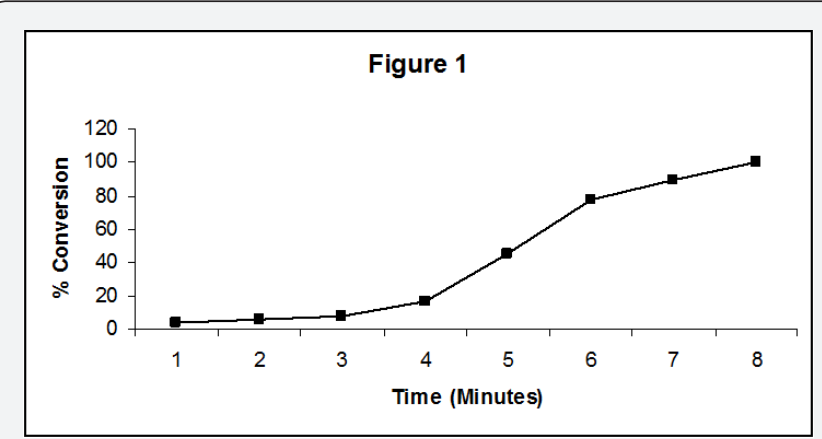

Figure 2: Photopolymerization of $\mathrm{CHO} 1$ and $4 \mathrm{VCHD} 2$ by $\operatorname{Re}(\mathrm{CO})_{5} \mathrm{Cl}$.

Polymerization of $\mathrm{CHO}$ monomer 1 proceeds through the opening of the epoxide ring to give soluble polymer poly (cyclohexene oxide), the product is long sequences of cyclohexane rings interlinked by oxygen atoms, Figure 3, however; the polymerization of the diepoxide monomer 2 was found to proceeds through the opening of both epoxide ring to give crosslinked polymer of poly (4-VCHD), as shown in Figure 4. Evidence for the structure of poly $4 \mathrm{VCHD}$ was obtained by studying the FTIR spectrum of the polymer obtained under different conditions. Typical epoxide bands characteristic of the monomer at 890,850 and $913 \mathrm{~cm}^{-1}$ are missing from the polymer spectra, and a new very powerful band at 1087 and $1157 \mathrm{~cm}^{-1}$ associated with the ether linkage is present. The new band at $108 \mathrm{~cm}^{-1}$ is the strongest, and its position varies slightly with chemical structure of the polymer. The important characteristic in the polymerization reaction of 4-VCHD by rhenium carbonyls is the start of the polymerization of both of the epoxy rings at the early stages of polymerization, a crosslinked polymer was obtained at $2 \%$ conversion is an idication of reaction of both epoxides at the same time (Figure 4). Thermal polymerization of 4VCHD by dirhenium decacarbonyl and the rhenium pentacarbonyl halides is shown in (Table 2).

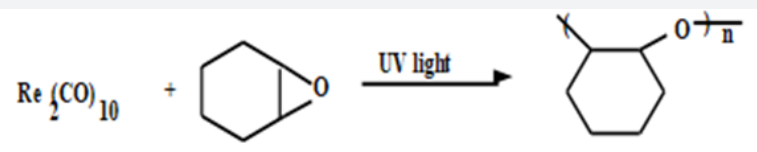

Figure 3: Polymerization of $\mathrm{CHO} 1$

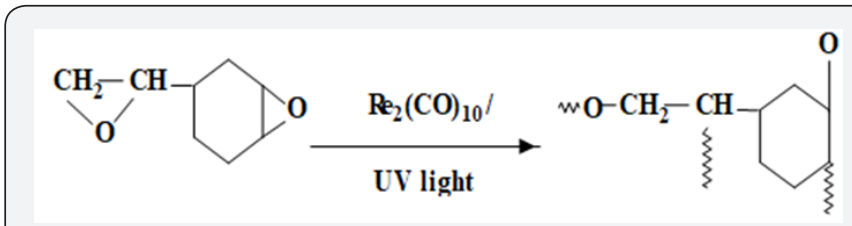

Figure 4: Polymerization of 4VCHD 2.

Table 2: Thermal polymerization of 4-VCHD (bulk), initiator effect on the gel time. [initiator] $=2.50 \times 10^{-3} \mathrm{M}$.

\begin{tabular}{|c|c|c|}
\hline Initiator & Gel Time at $\mathbf{7 5}^{\circ} \mathrm{C}$ & Gel Time at $\mathbf{2 5}^{\circ} \mathbf{C}$ \\
\hline & (Hours) & (hours) \\
\hline $\operatorname{Re}_{2}(\mathrm{CO})_{10}$ & 2 hours & 72 \\
\hline $\operatorname{Re}(\mathrm{CO})_{5} \mathrm{Cl}$ & $10 \mathrm{mins}$ & 72 \\
\hline $\operatorname{Re}(\mathrm{CO})_{5} \mathrm{Br}$ & 3 mins & 72 \\
\hline $\operatorname{Re}(\mathrm{CO})_{5} \mathrm{I}$ & 2 mins & 72 \\
\hline
\end{tabular}

$\operatorname{Re}(\mathrm{CO})_{5} \mathrm{Cl}>\operatorname{Re}(\mathrm{CO}) 5 \mathrm{Br}=\operatorname{Re}_{2}(\mathrm{CO})_{10}>\operatorname{Re}(\mathrm{CO})_{5} \mathrm{I}$

Thermal polymerization of monomer 2 by the rhenium carbonyl halides proceed very slowly at $25^{\circ} \mathrm{C}$, and the gel time is 72 hours; and for polymerization at $75^{\circ} \mathrm{C}$ the gel time fall in the following sequence: $\operatorname{Re}(\mathrm{CO})_{5} \mathrm{I}>\operatorname{Re}_{2}(\mathrm{CO})_{10}>\operatorname{Re}(\mathrm{CO})_{5} \mathrm{Br}>\operatorname{Re}(\mathrm{CO})_{5} \mathrm{Cl}$ (Table 2). This activity is in acrodance with the bond strength between the halide and the rhenium atom. Polymer obtained as a white powder, insoluble in all solvents.

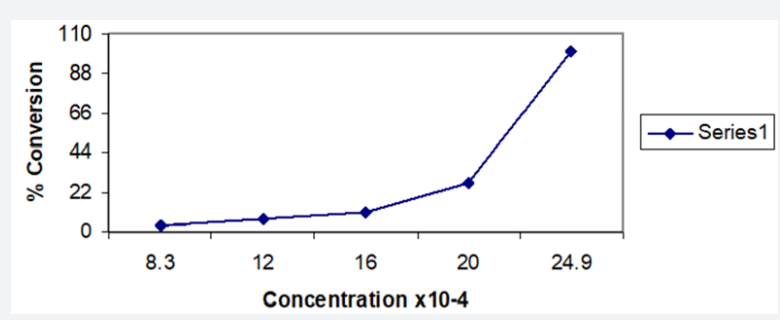

Figure 5: Bulk photopolymerization of monomer 2 by $\operatorname{Re}(\mathrm{CO})_{5} \mathrm{Cl}$, time $=5$ minutes

A comparison beteen the bulk photopolymerization of $\mathrm{CHO}$ 1 and 4 VCHD 2 under the same conditions using $\operatorname{Re}(\mathrm{CO})_{5} \mathrm{Cl}$ $\left(2.50 \times 10^{-3} \mathrm{M}\right)$, shows the required time for complete polymerization (100\% conversion) of CHO 1 is 10 minutes and for 4VCHD 2 is 5 minutes, this indicates that the reactivity of monomer 2 almost is twice as that of monomr 1 , and both epoxide rings react and opened at the same time.

\section{Effect of initiator concentration}

The effect of $\operatorname{Re}(\mathrm{CO})_{5} \mathrm{Cl}$ concentration on $4 \mathrm{VCHD}$ photopolymerization in the range $\left(1.80 \times 10^{-3}\right.$ to $\left.3.69 \times 10^{-3} \mathrm{M}\right)$ for fxied time of 5 minutes and without solvent is shown in Figure 5, this indicates an increase in the rate of polymerization as the initiator concentration increases, polymer obtained as crystalline solid which is insoluble in aromatic and halogenated hydrocarbon solvents. 


\section{Poly4-VCHD characterization}

The polymer structure was identified by FTIR spectroscopy. The FT-IR spectrum of poly (4-VCHD) prepared photochemically and thermally by $\operatorname{Re}(\mathrm{CO})_{5} \mathrm{Cl}$ and $\mathrm{Re}_{2}(\mathrm{CO})_{10}$. Poly (4-VCHD) pre- pared photochemically by by $\mathrm{Re}_{2}(\mathrm{CO})_{10}$ shows the $\mathrm{OH}$ group at 3400 , aliphatic $\left(\mathrm{CH}_{2}, \mathrm{CH}\right)$ at 2960, 2850, and 1920, 1720 (CO) and 1655,1470 ( six member ring in polymer), 1440, 1050, 1087 and $913 \mathrm{~cm}^{-1}$ for the C-O-C stretching frequency $[8,9]$. These assignment suggest that the catalyst is attached to the poly (4-VCHD).

\section{Proposed polymerization mechanism}

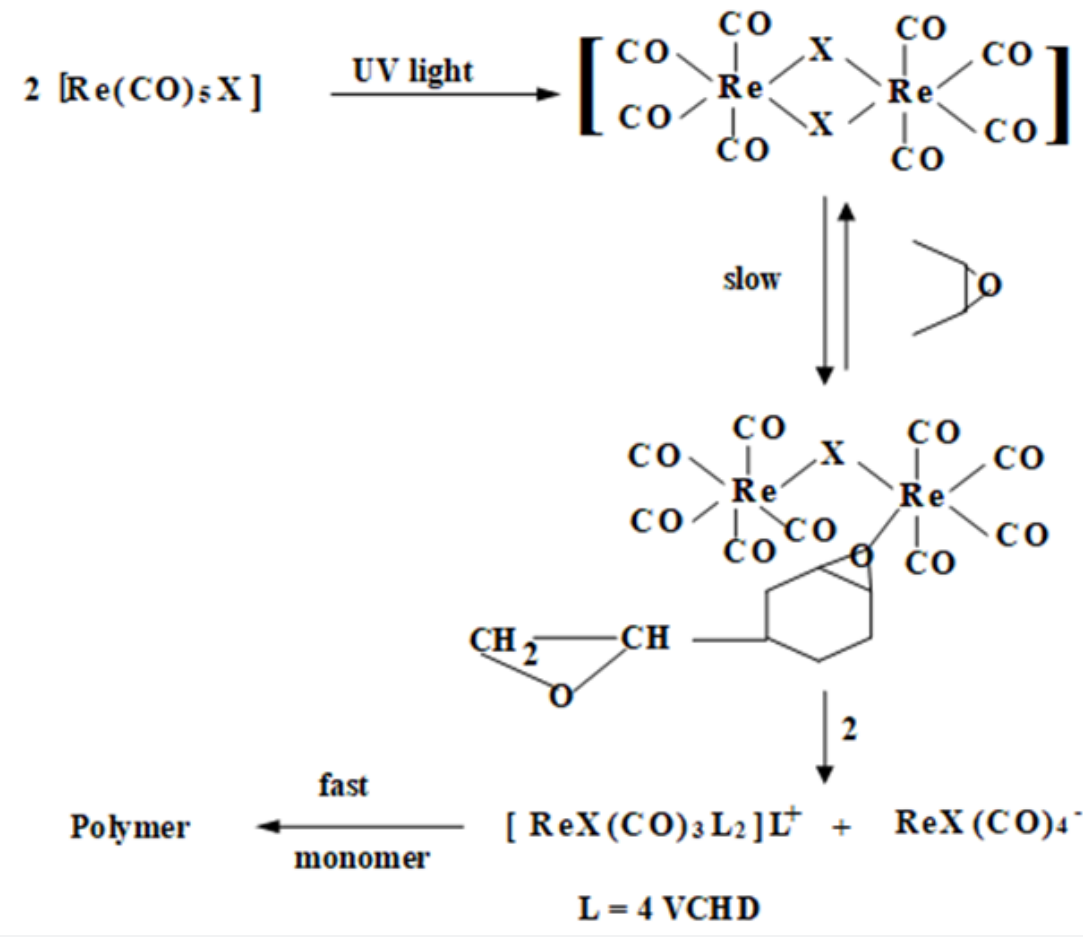

Figure 6: Proposed mechanism of 4-vinyl-1-cyclohexene diepoxide polymerization.

The photodisproportionation of the complex $\left(\mathrm{Re}(\mathrm{CO})_{5} \mathrm{Cl}\right.$ is shown in (Figure 6), L represent a coordinating monomer. The dimerization of the photoexited $\operatorname{Re}(\mathrm{CO})_{5} \mathrm{X}$ is bridged through the halogen $(\mathrm{X})$, the bridges is broken by the monomer (4-VCHD), further addition of the monomer to the complex induce the initial propagation reaction. For photoinitiation of the polymerization of 4-VCHD by $\operatorname{Re}_{2}(\mathrm{CO})_{10}$ compounds, we suggested the same mechanism as reported for photopolymerization of cyclohexene oxide [8], the growth of the two epoxide functional groups will leads to crosslinked polymer(Figure 6).

\section{Conclusions}

Rhenium carbonyls are effective photoinitiator for the polymerization of (4-VCHD) without cocatalyst, in absence of UV light long reaction time is required. Polymerization by Rhenium carbonyls shows that both epoxide ring were opened. The rate of polymerization depends on the structure of the rhenium carbonyl. Insoluble polymer was obtained in photo or thermal polymerization even at low conversion of monomer.

\section{References}

1. Breitigam WV (1983) Modern Plastic Encyclopedia p. 31.

2. Watt WR (1979) Epoxy Resin Chemistry. In: Bauer RS (Ed.), ACS Symposium Series p. 144.

3. Abu-Abdoun I I (1999) I Polym Inter 48: 1197

4. Abu-Abdoun I I (2000) Designed Monomer and Polymers 3: 171.

5. Yagci Y, Hizal G, Aydogan AC (1985) Studies on the promoted polymerization of 4-Vinylcyclohexendioxide Eur Polym J 21(1): 25-27.

6. Usanmaz A, Asaid A (1986) Polymerization of 1,2-epoxy-4epoxyethylcyclohexane. J Polym Sci Part A: Polym Chem 24(12): 32633269.

7. Abu Abdoun II, Aale Ali (1993) Europ polym J (29): 1439-1443.

8. Pretsch E, Clerc T, Seibl J, Simon W (1989) Spectral Data for Structural Determination of Organic Compounds. Springer Verlag, Berlin.

9. Heise MS, Martin GC (1989) Curing mechanism and thermal properties of epoxy-imidazole systems. Macromolecules 22(1): 99-104.

\section{Acknowledgement}

Support to this work from university of sharjah is greatfully acknowledged. 
(C) Commons Attribution 4.0 License BY

\section{Your next submission with Juniper Publishers}

will reach you the below assets

- Quality Editorial service

- Swift Peer Review

- Reprints availability

- E-prints Service

- Manuscript Podcast for convenient understanding

- Global attainment for your research

- Manuscript accessibility in different formats

( Pdf, E-pub, Full Text, Audio)

- Unceasing customer service

Track the below URL for one-step submission https://juniperpublishers.com/online-submission.php 